\title{
Smart ATM System using AVR Microcontroller
}

\author{
Pratik Pise, Kasturi Bidwai, Samiksha Bandbuche, Shashant Jaykar \\ Department of Electronics and Telecommunication Engineering, \\ Rajiv Gandhi College of Engineering and Research, Nagpur, India
}

\begin{abstract}
In today's Modern World, Autonomous Systems plays an Important Role in our day to day Life. As the Social Computerization and Automation have drastically increased, it can be seen evidently where the number of ATM Centers increases rapidly. In the era of digitalization, everyone needs money without interaction with bank at any time. So the ATM (Automotive Teller Machines) are installed everywhere in the localities. As the number of ATMs increased, prevention of theft and security of customer is the prime objective. At present, security systems are not highly secured as they are only provided with alarm system. This project deals with design and implementation of ATM security system using RFID and GSM Modem. The prime objective of this project is, to secure the ATM system using RFID and GSM modem. In this project, user have to use RFID card to access the machine then OTP is send to the mobile number. After entering OTP the amount is to be enter. Then user can collect the money. When a thief enters and tried for unwanted issues for user the user have to enter the OTP in reverse form then SMS is send to police. The project is implemented and worked successfully.
\end{abstract}

Keywords: Automotive Teller Machines (ATM), Radio Frequency Identification (RFID), Global system for mobile communication (GSM Modem), One Time password (OTP).

\section{I.INTRODUCTION}

In present scenario, ATM has become one of the most important facilities in our day to day life. This facility enables us to withdraw the money from the authorized account at any time. Security is the major aspect, as the need of ATM is increasing day by day. Security systems are the demands of the day, which helps to avoid theft. Although the banks are deploying security personnel at the ATM spots, but the security arrangement is not quite good enough to secure the facility in case a group of thieves tries to stole the ATM machine. Recently we have seen many cases wherein a group of people entering into ATM and overpowering the security personnel and stole the money from the ATM. Generally a single person is unable to handle the gang of robbers. Thus an automatic security system plays very important role to avoid robberies.

Most Civilians use ATM's regularly. A good example can be a financial transaction, ease of money exchange etc. So there exists an important factor called security. The Crime rates involved in Financial Organizations have increased tremendously. Over past few years - " $90 \%$ of Crimes in ATM centers in the form of Robbery". This issue poses a serious threat to both Bank Management and Civilians. Therefore, this Study proposes a Solution to minimize the ATM Robbery in real time by means of Embedded Systems and GSM technology. The Main motive of this design is to Prevent ATM theft. Many real time Incidents around us has been the main motivation of this Project.

RFID system provides an efficient and simple method for identification. There are other methods for identification like barcode, optical character recognition, biometric and smart card but possible area of use is much larger for RFID system. Like transportation and logistics, security and animal tagging, postal tracking, time and attendance and road toll management. RFID tags act as small transponders that respond to quires from a reader wirelessly and transmitting a serial number or similar identifier

The system uses RFID reader to detect the user tag and GSM to send the sms OTP to user mobile number. After entering the OTP the machine ask to enter the money and user can collect the money. Also if the money not available then LCD display NO CASH. when the person enter to atm machine then led light will ON automatically and off when no one there to save the power.

Theft protection also included by entering reverse OTP the sms sent to the police station for protection.

\section{SYSTEM ARCHITECTURE OF SMART ATM SYSTEM}

The architecture of smart ATM system using AVR microcontroller consists of RFID Reader, GSM Module, LCD Display, PIR Sensor, IR Sensor, IR Sensor, Arduino nano, LEDs, 4*3 Matrix Keypad, LM 0575 Regulator. The complete working of our project consists of two major parts first part deals with working of GSM and RFID and second one shows the combined working of AVR Microcontroller and GSM module. In this project we analysed what is the problem faced by the people in the existing technology. Especially Multi-factor Authentication (MFA) method provides more 


\section{International Advanced Research Journal in Science, Engineering and Technology}

Vol. 8, Issue 6, June 2021

\section{DOI: 10.17148/IARJSET.2021.8644}

complexity to the user. This project helps to overcome the problem of complexity and provides easiest way to secure the ATM transaction.

The main objective is to design a Smart ATM machine using RFID and GSM technologies. In this project we use wireless smart card ie. RFID.

Whenever person scan smart card and enters amount to be withdrawn onto the ATM machine, the system checks whether the card is authorized or not. If the card is authorized, the proposed system uses GSM modem for sending OTP from ATM to the user. If user correctly entered OTP from mobile then transaction takes place.

This project uses a 'ATmega32A Microcontroller' from AVR family. The primary objective of this project is to detect SMART CARD.

To demonstrate this project, we assign a default amount to a specific smart card, when we check that card with RFID READER we can withdraw cash from ATM. The program there after takes over to send an OTP through GSM modem interfaced through TX, RX pin to the microcontroller. An LCD is also interfaced with the microcontroller to display required information. If user correctly entered OTP from mobile then transaction takes place. If the user is in danger he/she can enter the OTP in reverse direction, this will unlock the shutter and the message will be sent to manager and police. If the user enter the wrong OTP in three successful times then the transaction will be blocked for a day. If there is insufficient balance in ATM then the system will sense it and send the message to manager. Thus, the proposed project is designed to demonstrate a working model of smart ATM using AVR microcontroller.

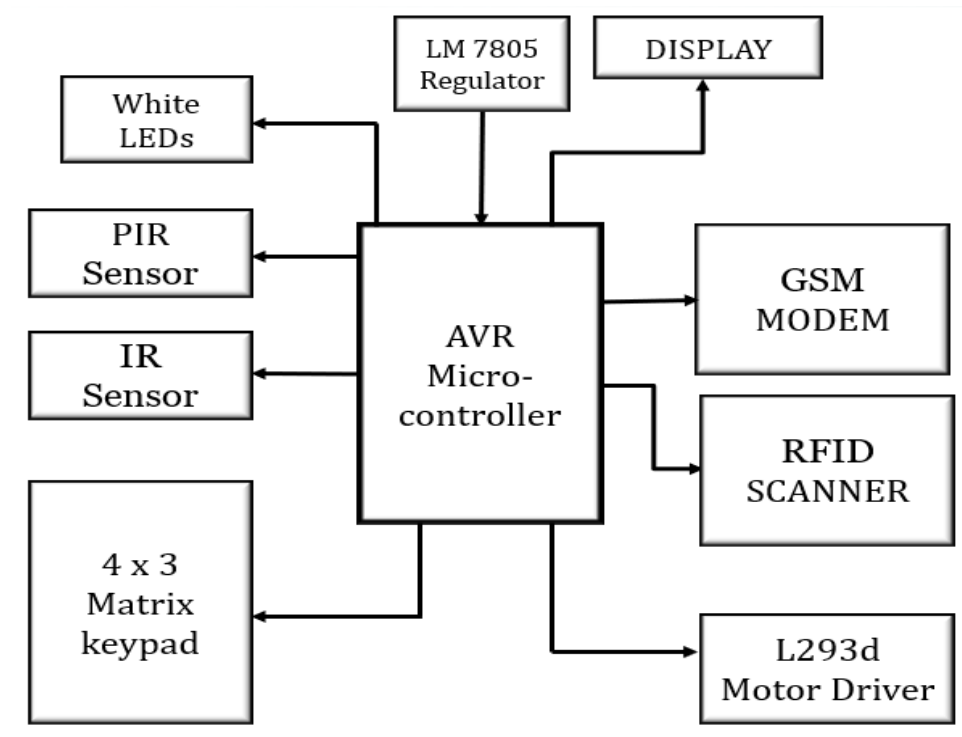

Fig 1. Architecture of Smart ATM System

\section{MODULES DESIGN OF SMART ATM SYSTEM}

This section presents the design of different modules like Arduino nano, LCD Display, EM18 RFID Reader, Voltage Regulator,

\section{A. Arduino nano}

Arduino Nano circuit board with Arduino IDE is capable of reading analog or digital input signals from different sensors, activating the motor, turning LED on/off and do many other such activities. All functionalities are performed by sending a set of instructions to the ATtmega328 main microcontroller, on the board via Arduino IDE. The Arduino board also includes Power USB, Power (Barrel Jack), voltage regulator, crystal oscillator, voltage pins (3.3v,5v,gnd,vin), A0 to A5 analog pins, icsp pin, power led indicator, tx and rx leds, 14 digital input/output pins, Aref, and Arduino reset The Arduino Uno is a microcontroller board, based on the ATmega328. The Uno board functioning is different from all other boards in that it does not use the FTDI USB to serial driver chip. Instead, the Atmega328 is programmed as a USB to serial converter. The ATmega328 is a low power CMOS 8-bit microcontroller based on the AVR enhanced RISC architecture structure

The Arduino project started in 2003 as a program for students at the Interaction Design Institute Ivrea in Ivrea, Italy,[2] aiming to provide a low-cost and easy way for novices and professionals to create devices that interact with their 


\section{International Advanced Research Journal in Science, Engineering and Technology}

Vol. 8, Issue 6, June 2021

\section{DOI: $10.17148 /$ IARJSET.2021.8644}

environment using sensors and actuators. Common examples of such devices intended for beginner hobbyists include simple robots, thermostats and motion detectors.

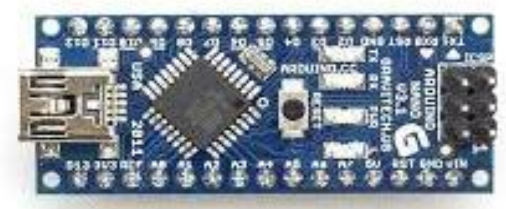

Fig 2. Picture of Arduino Nano

\section{B. LCD Display}

LCD (Liquid Crystal Display) screen is an electronic display module and finds a wide range of applications. A 16x2 LCD display is a very basic module that has 2 controllers with 16 Pins which is very commonly used in various devices and circuits. These modules are preferred over seven segments and other multi-segment LEDs as they are economical; easily programmable; have no limitation of displaying special \& even custom characters (unlike in seven segments), animations. The status of the system is displayed using LCD.

A liquid-crystal display (LCD) is a flat-panel display or other electronically modulated optical device that uses the lightmodulating properties of liquid crystals. Liquid crystals do not emit light directly, instead using a backlight or reflector to produce images in color or monochrome.[1] LCDs are available to display arbitrary images (as in a general-purpose computer display) or fixed images with low information content, which can be displayed or hidden, such as preset words, digits, and seven-segment displays, as in a digital clock. They use the same basic technology, except that arbitrary images are made up of a large number of small pixels, while other displays have larger elements. LCDs can either be normally on (positive) or off (negative), depending on the polarizer arrangement. For example, a character positive LCD with a backlight will have black lettering on a background that is the color of the backlight, and a character negative LCD will have a black background with the letters being of the same color as the backlight. Optical filters are added to white on blue LCDs to give them their characteristic appearance.

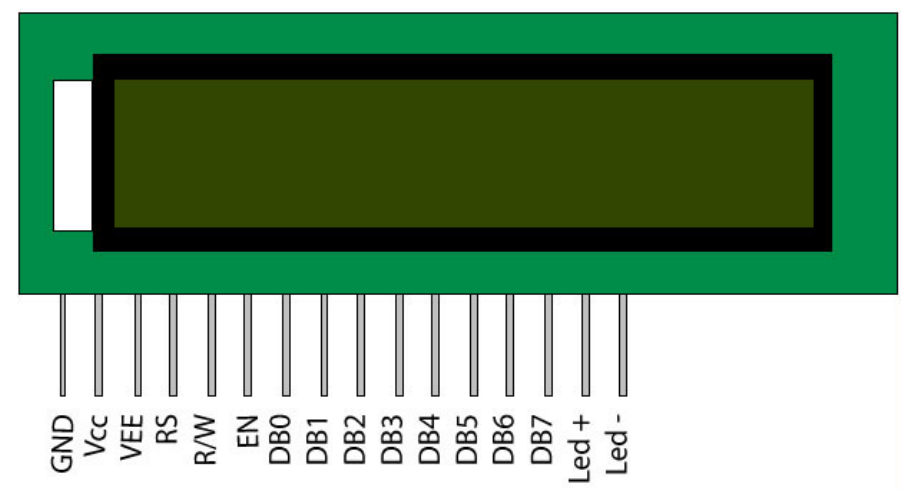

Fig 3. Picture of LCD display.

A 16x2 LCD means it can display 16 characters per line and there are 2 such lines. In this LCD each character is displayed in 5x7 pixel matrix. This LCD has two registers, namely, Command and Data.

The command register stores the command instructions given to the LCD. A command is an instruction given to LCD to do a predefined task like initializing it, clearing its screen, setting the cursor position, controlling display etc. The data register stores the data to be displayed on the LCD. The data is the ASCII value of the character to be displayed on the LCD. Click to learn more about internal structure of a LCD

\section{EM18 RFID Reader}

RFID READER There are three types of RFID readers based on their frequency ranges, low frequency, high frequency and ultrahigh frequency. This EM-18 is a low frequency (125 KHz) RFID reader with serial output with at range of 8 $12 \mathrm{~cm}$. It is a compact unit with built in antenna and can be directly connected to the PC using RS232 protocol [4]. It is an inexpensive solution for this RFID based application. The Reader module comes with an on-chip antenna and can be powered up with a $5 \mathrm{~V}$ power supply 


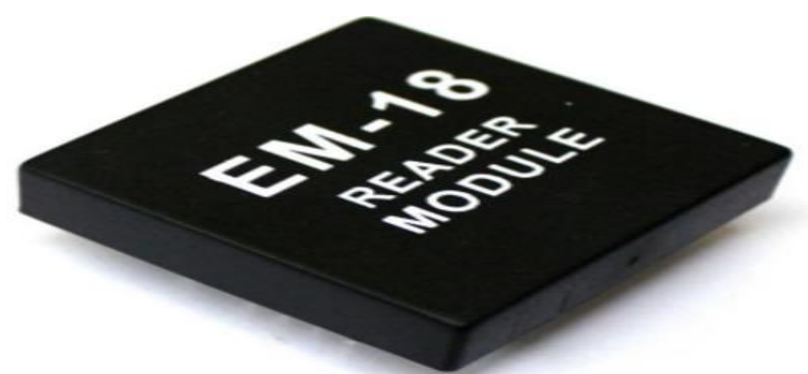

Fig 4. Picture of RFID Reader Module

The EM-18 RFID Reader module operating at $125 \mathrm{kHz}$ is an inexpensive solution for your RFID based application. The Reader module comes with an on-chip antenna and can be powered up with a 5V power supply. Power-up the module and connect the transmit pin of the module to recieve pin of your microcontroller. Show your card within the reading distance and the card number is thrown at the output. Optionally the module can be configured for also a weigand output. Typical Applications e-Payment e-Toll Road Pricing e-Ticketing for Events e-Ticketing for Public Transport Access Control PC Access Authentication Printer / Production Equipment.

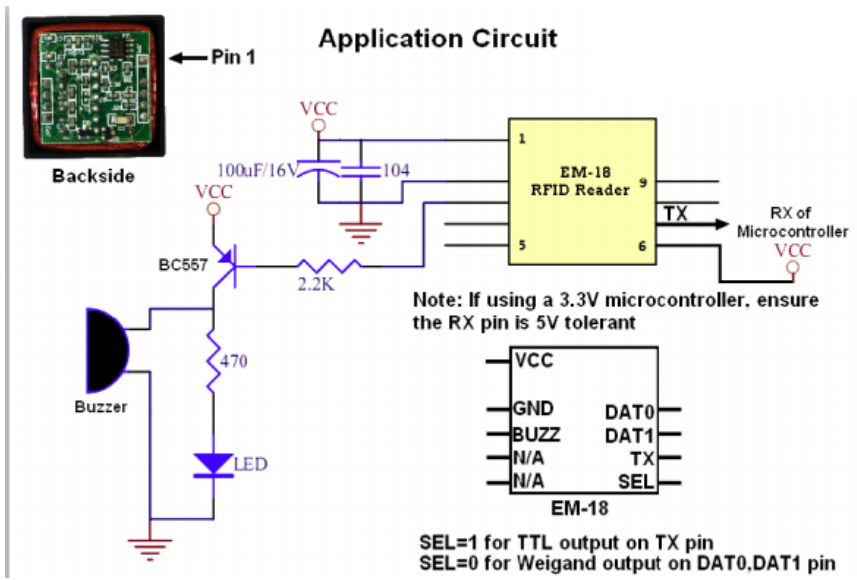

Fig 5. Application Circuit of RFID Reader

\section{Voltage Regulator}

Voltage sources in a circuit may have fluctuations resulting in not providing fixed voltage outputs. A voltage regulator IC maintains the output voltage at a constant value. 7805 IC, a member of 78xx series of fixed linear voltage regulators used to maintain such fluctuations, is a popular voltage regulator integrated circuit (IC). The $\mathrm{xx}$ in $78 \mathrm{xx}$ indicates the output voltage it provides. 7805 IC provides +5 volts regulated power supply with provisions to add a heat sink.

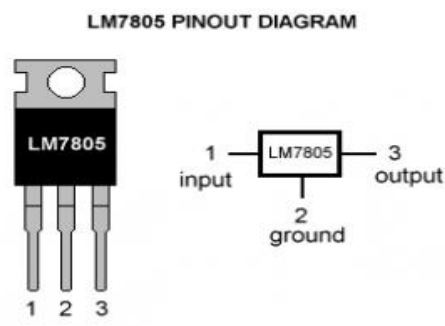

Fig 6. Picture of LM7805 PINOUT Diagram

Input voltage range $7 \mathrm{~V}-35 \mathrm{~V}$

Current rating $\mathrm{Ic}=1 \mathrm{~A}$

Output voltage range $\mathrm{VMax}=5.2 \mathrm{~V}, \mathrm{VMin}=4.8 \mathrm{~V}$ 


\section{International Advanced Research Journal in Science, Engineering and Technology}

Vol. 8, Issue 6, June 2021

DOI: $10.17148 /$ IARJSET.2021.8644

\begin{tabular}{|c|c|c|c|}
\hline \multirow[b]{2}{*}{$\begin{array}{l}\text { Pin } \\
\text { No. }\end{array}$} & \multicolumn{3}{|c|}{ TABLE I PIN DETAILS OF 8705 IC } \\
\hline & Pin & Function & Description \\
\hline 1 & INPUT & Input voltage $(7 \mathrm{~V}-35 \mathrm{~V})$ & $\begin{array}{l}\text { In this pin of the IC positive unregulated } \\
\text { voltage is given in regulation. }\end{array}$ \\
\hline 2 & GROUND & Ground (OV) & $\begin{array}{l}\text { In this pin where the ground is given. } \\
\text { This pin is neutral for equally the input } \\
\text { and output. }\end{array}$ \\
\hline 3 & OUTPUT & $\begin{array}{l}\text { Regulated output; } 5 \mathrm{~V}(4.8 \mathrm{~V}- \\
5.2 \mathrm{~V})\end{array}$ & $\begin{array}{l}\text { The output of the regulated } 5 \mathrm{~V} \text { volt is } \\
\text { taken out at this pin of the IC regulator. }\end{array}$ \\
\hline
\end{tabular}

\section{E. PIR Sensor}

PIR sensors allow you to sense motion, almost always used to detect whether a human has moved in or out of the sensors range. They are small, inexpensive, low-power, easy to use and don't wear out. For that reason they are commonly found in appliances and gadgets used in homes or businesses. They are often referred to as PIR, "Passive Infrared", "Pyroelectric", or "IR motion" sensors.

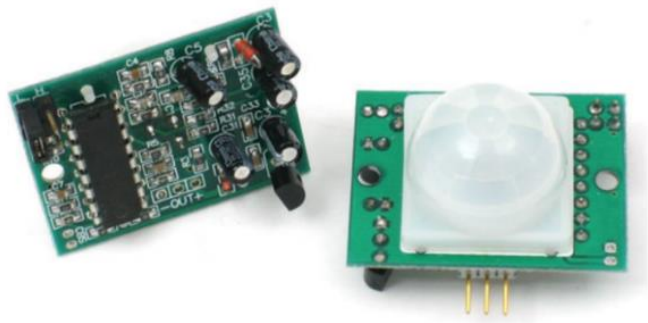

Fig 7. Picture of PIR Sensor

PIRs are basically made of a pyroelectric sensor (which you can see above as the round metal can with a rectangular crystal in the center), which can detect levels of infrared radiation. Everything emits some low level radiation, and the hotter something is, the more radiation is emitted. The sensor in a motion detector is actually split in two halves. The reason for that is that we are looking to detect motion (change) not average IR levels. The two halves are wired up so that they cancel each other out. If one half sees more or less IR radiation than the other, the output will swing high or low. PIR sensors are more complicated than many of the other sensors explained in these tutorials (like photocells, FSRs and tilt switches) because there are multiple variables that affect the sensors input and output.
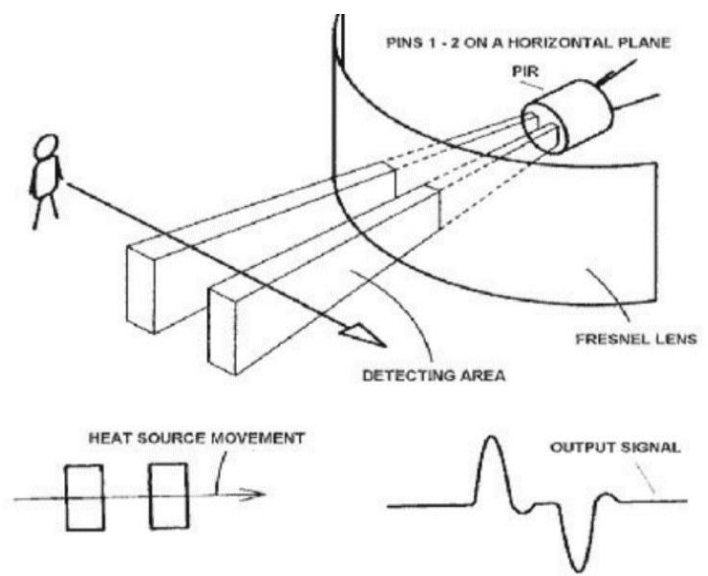

Fig 8. Pictorial Representation of working of PIR Sensors 


\section{International Advanced Research Journal in Science, Engineering and Technology}

Vol. 8, Issue 6, June 2021

DOI: $10.17148 /$ IARJSET.2021.8644

\section{F. GSM MODULE}

A GSM modem or GSM module is a hardware device that uses GSM mobile telephone technology to provide a data link to a remote network. From the view of the mobile phone network, they are essentially identical to an ordinary mobile phone, including the need for a SIM to identify themselves to the network. GSM modems typically provide TTLlevel serial interfaces to their host. They are usually used as part of an embedded systems.

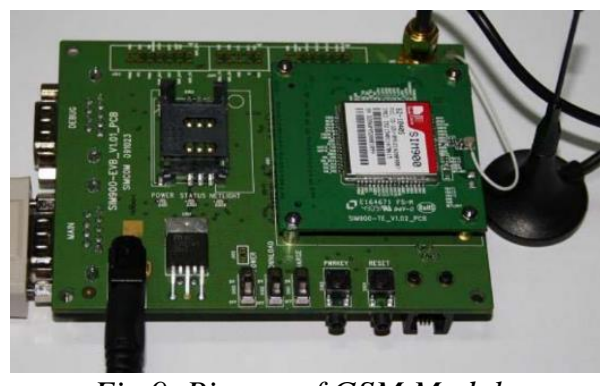

Fig 9. Picture of GSM Module

\section{PROGRAM IDE}

The Arduino integrated development environment (IDE) is a cross-platform application (for Windows, macOS, Linux) that is written in the programming language Java. It originated from the IDE for the languages Processing and Wiring. It includes a code editor with features such as text cutting and pasting, searching and replacing text, automatic indenting, brace matching, and syntax highlighting, and provides simple one-click mechanisms to compile and upload programs to an Arduino board. It also contains a message area, a text console, a toolbar with buttons for common functions and a hierarchy of operation menus. The source code for the IDE is released under the GNU General Public License, version 2.

The Arduino IDE supports the languages $\mathrm{C}$ and $\mathrm{C}++$ using special rules of code structuring. The Arduino IDE supplies a software library from the Wiring project, which provides many common input and output procedures. User-written code only requires two basic functions, for starting the sketch and the main program loop, that are compiled and linked with a program stub main() into an executable cyclic executive program with the GNU toolchain, also included with the IDE distribution. The Arduino IDE employs the program avrdude to convert the executable code into a text file in hexadecimal encoding that is loaded into the Arduino board by a loader program in the board's firmware.

\section{RESULT \& SUMMARY}

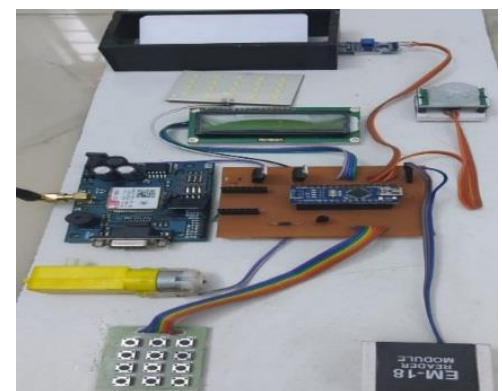

- $\quad$ Provide Convenience to Customer. Customer able to do financial transactions conveniently with the use of ATMs.

- Offer 24×7 Service.

- Reduce Banks Workload.

- Access to Bank Account from Anywhere.

- Minimizes Transactions Cost.

- Charges Fees.

- Limitation on Cash Withdrawal. 


\section{International Advanced Research Journal in Science, Engineering and Technology}

Vol. 8, Issue 6, June 2021

DOI: $10.17148 / I A R J S E T .2021 .8644$

\section{CONCLUSIONS}

The RFID based security and attendance system is more secure and fast responded as compared to the other system like biometric. Security plays an important role in our day to day life and it is need of the hour for all of us. Due to lack of employment, poverty, some people are forced to involve in Robbery. Burglary in ATM centres is nowadays increasing evidently. So Security to ATM centre is a must, in order to safeguard both human lives and money. Our Design will turn out to be the perfect solution to prevent Robbery in ATM centres. We have reduced the disadvantages and our design ensures security for both human life and money.

\section{REFERENCES}

[1]. M.R.Rieback, B.Crispo, \& A.S.Tanenbaum, "The Evolution of RFID Security"; Pervasive Computing, IEEE Volume 5, Issue 1, Jan.- Mar. 2006.

[2]. V. Subramanian, P. C. Chang, D. Huang, J. B. Lee, S. E. Molesa, D. R. Redinger, and S. K.Volkman, "All-printed RFID Tags: Materials, Devices, and Circuit Implications", VLSI Design, 2006

[3]. Yuvraju.M, Pranesh K.A. "Fair price shop automatedvending machine design using RFID and GSM communication technology" International journal for research in applied science and engineering technology(IJRASET) volume4 Issue VI, June2016, www.ijraset.com

[4]. (inventors: ryoheikondo, uruoharashima; daigosunouchi, all of gunma, japan) "Automatic coffee vending machine being able to serve a straight coffee and a blended coffee selectively " 800 Rahul Jadhv, Mrunali Jejurkar, Pranita Kave \& Prof. H.P. Chaudhari [5] Feng-Cheng Lin a, $\Uparrow$, HsinWen Yu a, Chih-Hao Hsu a, Tzu-Chun gb "Recommendation system for localized products in vending machines"

[5]. K.R.Nimisha1, K.Indumathi2, R.Divyamani3, R.Kavya4, K.Gowrimanokari5 "Smart Newspaper Vending Machine" [5] Asian Journal of Applied Science and Technology (AJAST) Volume 1, Issue 1, Pages 131-136, February 2017

[6]. Preetilatha $\mathrm{R}^{* 1}$, Ramkumar R\#2, Ramesh S.M**3, Kiruthika S\#4, Bharani M*5 "Stationery Vending Machine" International Journal of Innovative Science, Engineering \& Technology, Vol. 1 Issue 9, November 2014.

[7]. Ana Monga1, Balwinder Singh "Finite State Machine based Vending Machine Controller with Auto-Billing Features" International Journal of VLSI design \& Communication Systems (VLSICS) Vol.3, No.2, April 2012. 